Musées, Patrimoine et Culture scientifiques et techniques

$186 \mid 2019$

novembre-décembre 2019

\title{
Conceptions opposées du rôle du musée
}

\section{Serge Chaumier}

\section{OpenEdition}

Journals

Édition électronique

URL : http://journals.openedition.org/ocim/3430

DOI : 10.4000/ocim.3430

ISSN : 2108-646X

Éditeur

OCIM

Édition imprimée

Date de publication : 1 novembre 2019

Pagination : 25-27

ISSN : 0994-1908

Référence électronique

Serge Chaumier, «Conceptions opposées du rôle du musée », La Lettre de l'OCIM [En ligne], 186 | 2019, mis en ligne le 01 novembre 2020, consulté le 25 janvier 2021. URL : http://journals.openedition.org/ ocim/3430; DOI : https://doi.org/10.4000/ocim.3430

Ce document a été généré automatiquement le 25 janvier 2021.

Tous droits réservés 


\title{
Conceptions opposées du rôle du musée
}

\author{
Serge Chaumier
}

1 Les musées sont pluriels, de par leur histoire, leurs collections et leurs spécificités. Il serait illusoire de penser normaliser la richesse du paysage muséal avec des standards internationaux. Ils n'ont pas à répondre à des rôles tous identiques, même si des tendances les influencent sur le long terme et si dégager des points communs peut servir leur développement. Le débat en cours invite à penser deux paradigmes attachés au rôle et à la vocation des musées de service public. Ces cadres de pensée sont largement inconscients et surdéterminent ensuite actions, principes, moyens et choix d'organisation. Chaque modèle est subdivisé en deux visions, et peu ou prou, la profession se répartit globalement dans ces quatre approches.

\section{Paradigme 1 :}

\section{"les musées, ce sont d'abord des collections »}

2 Tout le reste ne vient que compléter ce principe. Les acquisitions pour enrichir, la conservation et l'inventaire: "le socle et le principe même du musée ». La recherche est liée à l'enrichissement d'un fond perçu comme déterminant et prioritaire. La communication ne vient qu'en plus, comme en complément. Il est symptomatique que les définitions successives aient toujours proposé cet ordre, en finissant par les publics.

$3 \quad 1.1$ - Cette représentation commune se clive en deux approches. La première est exprimée, mezzo-voce, par les plus réactionnaires des commentateurs, et que la plupart des professionnels n'osent exprimer, du moins publiquement. Le propos s'inscrit dans la lignée d'un Marc Fumaroli qui estime que le ministère de la Culture s'est fourvoyé en prétendant agir pour tous, et que les institutions culturelles sont d'abord pour ceux qui savent les apprécier, esthètes, savants, bref pour une élite qui dispose de la culture et qui vient se délecter. Les autres sont au mieux des invités que l'on supporte. Les discours critiques formulés envers les formes de médiation culturelle 
en viennent même à réhabiliter l'absence de médiation comme mode privilégié d'accès aux œuvres. Ce courant minoritaire s'inscrit dans une longue tradition aristocratique de la culture. Depuis trente ans, un professionnel n'oserait plus tenir de tels propos, sauf éventuellement dans le milieu de l'art contemporain... Il y a toutefois des représentants de cette position chez quelques journalistes et essayistes pour clamer haut et fort ce que certains pensent tout bas.

$4 \quad 1.2$ - L'autre courant, lui majoritaire, estime que le musée a des vocations éducatives. Il a dû s'ouvrir aux différents publics, aux scolaires et aux touristes qu'on appréhende comme des masses à civiliser. Depuis trente ans, se sont développés services pédagogiques et services des publics pour « évangéliser » en quelque sorte mécréants et ignares aux grandes œuvres de la culture. Le musée est donc d'abord constitué par des collections, et des savoirs, qu'il convient de porter à la connaissance de tous. Le schéma est peu ou prou une approche descendante qui vise à permettre l'élévation générale à la connaissance. Les reliques sont là pour témoigner de l'intérêt et de la grandeur d'une culture devant laquelle on est amené à s'incliner. Les experts, estiment essentiel de transmettre leur savoir, les informations qu'ils ont jugées intéressantes et légitimes. Le musée-église s'est mué en musée-école, puisqu'il s'agit in fine de le penser comme une école-bis. Il n'est qu'à considérer bien des expositions pour se rendre compte combien cette description n'est pas caricaturale. C'est ce modèle qui est en train de craquer face aux mutations contemporaines.

\section{Paradigme 2 :}

\section{"Le musée a vocation à servir la société et à se mettre au service des gens"}

5 Le second paradigme se déploie depuis trente ans, depuis la contre-culture, depuis les musées communautaires et la déclaration de l'Icom à Santiago (1972) et vise à décoloniser la culture en déhiérarchisant les approches. Il renoue avec les origines révolutionnaires du musée, outil pour préparer l'avenir. Il a vocation de servir la société et de se mettre au service des gens. L'utilité sociale du musée est alors moins de préserver le patrimoine, qui n'est qu'un moyen et non une fin, que de permettre le "développement culturel », faire advenir une société épanouie. Le mot "éducation » utilisé pour définir le musée, prend alors deux sens, celui de l'instruction, auquel se rattache la vision descendante précédente et le terme d'éducation au sens où l'employait Condorcet (et auquel se rattache les tenants de ce second paradigme).

62.1 - Le terme bien commode de «médiation culturelle» sert ainsi à masquer des profondes différences de conception, les premiers l'utilisent en place de démocratisation des savoirs, alors que les seconds entendent participer d'une démarche de "démocratie culturelle ", c'est-à-dire de permettre aux publics de se construire individuellement et collectivement. Les savoirs, comme les œuvres ou les objets, sont des outils, des instruments, au service du développement et de l'action culturelle. Les experts n'ont plus le dernier mot pour imposer leur culture. D'autres voix s'élèvent, qui peuvent interpréter autrement. Espace polyphonique, les publics ont des propos à échanger. Les laboratoires de recherche sont sortis de beaucoup d'institutions, du fait de l'impossibilité à faire comprendre à l'expert qu'il devait partager la parole et le pouvoir... Ce qui a été possible dans bien des musées de sciences 
est rarement le cas dans les musées d'art où l'expert demeure maitre à bord. Pour exemple, les médiations écrites sont souvent l'enjeu de cette tension, entre ceux qui la conçoivent comme un transfert de connaissances et ceux qui partent d'une logique des publics et usagers. Les professionnels sont souvent écartelés entre les demandes de la tutelle et de la hiérarchie et leur conviction de leur utilité sociale.

7 En France, l'organisation sociale des établissements est déterminée par une hiérarchie, et la plupart du temps les conservateurs dirigent les institutions. Ils sont formés dans le premier paradigme par le formatage académique qui les conditionne à penser le musée comme un lieu de préservation du patrimoine avant les objectifs culturels et sociaux. Le malaise professionnel va croissant, d'autant que le monde change et que les demandes sociales vis-à-vis de l'institution s'accroissent. Les services culturels, les services des publics sont écartelés entre une demande de diffusion d'informations des savoirsexperts par les autorités, et leur conviction que leur mission relève d'autres enjeux. Acteurs méritants d'un combat qui oppose de manière récurrente deux visions, les militants de la cause des publics doivent sans cesse faire la preuve de leur utilité (par exemple lorsque des crédits doivent se porter sur le développement d'actions culturelles ou sur une énième acquisition, ou encore sur des choix en matière de ressources humaines). L'équilibre est faussé du moment que hiérarchiquement les uns disposent de l'autorité sur les autres. La seule solution viable, telle qu'on la voit plus souvent à l'étranger, est une direction qui arbitre entre des services aux logiques différentes.

82.2 - Une seconde conception s'affirme de plus en plus au sein de ce second paradigme, encore minoritaire, elle est malgré tout portée par une tendance mondiale, du fait des mutations dans les pratiques culturelles des usagers et par une série de changements sociaux. Affirmant clairement la volonté de rompre avec une école-bis, elle affirme avec radicalité la vocation du musée à être un lieu d'émancipation et correspond à une demande sociale de plus en plus prégnante des usagers de "réalisation de soi ». La confrontation (à soi, à autrui, à l'altérité) et la co-construction (actions de partage, de dialogue, de participation, d'implication, de création...) permettent à tout un chacun de se questionner, de s'exprimer et de rencontrer, de construire le vivre ensemble.

Le décloisonnement des savoirs, la reconnaissance des capacités et des compétences de chacun, en relation avec les droits culturels de la déclaration de Fribourg ou des droits de la personne en vogue dans les pays anglo-saxons, la décolonisation de la culture et l'approche critique des savoirs experts, le refus de hiérarchisation des cultures, sont autant de facteurs qui viennent confirmer cette tendance. Le fait de se mettre au service des communautés, ou de manière moins polémique en France où ce terme fait débat, de permettre au citoyen de s'épanouir et de se réaliser vient renouer au final avec les origines même de la culture. Celle d'être non pas un synonyme d'accumulation des connaissances, mais une appropriation de celles-ci pour la construction d'un devenir individuel et collectif.

Cela vient remettre en cause une association qui vise à faire de la culture et de l'intelligence des synonymes. L'intelligence se caractérise moins par un niveau de connaissance que par le fait de savoir prendre de la distance critique, d'interroger, de questionner, de mettre en interprétation et en débat, de savoir créer, imaginer, développer, déployer des nouvelles formes et de nouvelles approches. Ce sont ces objectifs là que l'institution muséale, et la culture en général, se devraient de devoir accomplir, et non, encore une fois, de seulement transmettre des savoirs. À l'heure où 
la connaissance est accessible sur son smartphone, l'important est de savoir trier, sélectionner, proposer des cadres méthodologiques de développement de l'esprit critique. La mission principale d'une institution culturelle devrait être de susciter le désir. Les connaissances sont pour cela seulement des instruments dont on peut se servir pour déployer le champ des possibles.

Ces approches devraient valoir pour l'école et l'université... Nous pouvons nous interroger sur le fait que ce ne soit guère le cas et que l'on continue à viser à former "des chiens savants», comme le déplorait déjà Montaigne. L'idéologie qui vise à faire se superposer intelligence et accumulation des savoirs permet de maintenir un état de domination : suggérer aux catégories sociales les moins pourvues le fait « qu'elles n'ont pas de culture », comme le disaient souvent les catégories populaires, et implicitement qu'elles ne sont pas à mêmes de comprendre et de juger. La fonction sociale du mécanisme de la dévalorisation de soi est alors évidente. C'est cette croyance qui est en train de craquer, avec la remise en question des savoirs dominants et de la culture légitime, du fait de la montée en puissance critique depuis 50 ans. La réhabilitation des cultures populaires, par les sciences sociales, mais aussi par les artistes (pensons au texte au vitriol de Jean Dubuffet), nourrissent la crise du monde culturel et redonnent confiance aux damnés de la terre. Ceux-ci s'expriment, prennent de plus en plus la parole : la richesse ne réside ni dans l'accumulation matérielle, ni dans la compilation des connaissances, elle est dans l'agir de ce que l'on produit à partir d'elles.

Si l'école peut être comprise comme un instrument de reproduction des inégalités sociales, et de domination des classes dominantes par l'idéologie du mérite, le musée n'est pas en reste. Que produisent, par exemple, les institutions lorsqu'elles accueillent massivement les enfants des classes favorisées (comme le montrent les statistiques de fréquentation), leur donnant de ce fait des capacités supplémentaires pour dominer le jeu social? Les visites scolaires et les actions dites à destination du champ social ne venant que faiblement compenser une fréquentation massive par les mieux pourvus en capital culturel légitime. Le Centre Beaubourg a ainsi décidé courageusement de réserver le principal de ses actions culturelles aux plus défavorisés, puisqu'ils ont le plus besoin d'accompagnement. Ceci pourrait être un mot d'ordre fort pour l'ensemble des institutions. Une véritable politique en faveur de l'élargissement des publics devrait reposer sur un équilibre des crédits alloués par le ministère, les collectivités, ou les institutions entre les missions d'acquisition, de conservation, de recherche, d'entretien du patrimoine ou d'aide à la production artistique en général, et les crédits propres au développement culturel. Or, depuis la création du ministère, le déséquilibre est patent. Un simple rééquilibrage aurait un effet véritablement révolutionnaire. On pourrait alors se payer avec autre chose que la fausse monnaie de ses rêves ou arrêter de douter des intentions de la culture quand elle prétend viser à l'égalité alors qu'elle ne sert que les intérêts des classes favorisées.

13 Les définitions du musée peuvent ainsi donner lieu à des débats et même des perspectives passionnantes, et l'on comprend que les réactions soient si vives, à partir du moment où l'on touche à l'ordre social et aux impensées des discours tenus, largement idéologiques, à la construction des rapports de force, aux distributions des inégalités sociales. De cette dialectique émerge des approches radicales, et ce sont bien des choix de société qui s'imposent. En changeant l'utilité sociale des institutions, on se prend à espérer un accompagnement aux mutations sociétales nécessaires à la planète. 


\section{RÉSUMÉS}

Cet article est extrait du dossier "Vers une nouvelle définition du musée ? " dirigé par Ewa Maczek, directrice par intérim de l'Ocim. La définition du musée proposée depuis 2007 par l'Icom fait référence dans la sphère muséale mondiale. Si la volonté de faire évoluer cette définition fait sens, la proposition du Comité pour la Définition du musée, perspectives et potentiels (MDPP) de l'Icom a surpris bon nombre de professionnels et d'institutions, et tout particulièrement en France. La lettre de l'Ocim leur a ouvert ses pages pour qu'ils partagent leurs réactions.

\section{INDEX}

Mots-clés : politique du patrimoine, organisation internationale

\section{AUTEUR}

\section{SERGE CHAUMIER}

Enseignant-chercheur, responsable du master Expographie-Museographie à l'université d'Artois serge.chaumier@gmail.com 